\title{
Can Chinese Giants Become Multinational Companies?
}

\author{
Denis Depoux
}

\begin{abstract}
Being strong in revenue yet weak in globalization is a paradox for Chinese companies. Having benefited from a large domestic market and sparkling business innovation, Chinese companies are gigantic in size and entrepreneurial by nature. However, given the political polarization accelerated by the Coronavirus pandemic, Chinese companies are increasingly challenged by the global business community. Unfamiliarity with local customs, lack of communication, cultural differences and misperception are major issues that confront Chinese companies. Training and promotion of local employees and to increase the number of local managers, which will enable Chinese companies to navigate cultural barriers and build trust with potential foreign partners, helping them to become true MNCs.
\end{abstract}

Keywords Strong in revenue $\cdot$ Weak in globalization $\cdot$ Coronavirus $\cdot$ Local customs $\cdot$ Lack of communication $\cdot$ Cultural differences $\cdot$ Promotion of local employees

Last year, during a long assignment to review the strategy of a major player in China's technology industry, I addressed the Board of Management of the company and at one point said "You are not a multinational company, you remain a Chinese company". Forty percent of the revenues of this company were generated last year outside of China, so my remark was welcomed by a long silence in the room, followed by some chatter, until a key executive acknowledged that I was probably right...

What is a multinational company? Wikipedia tells us that "A multinational company (MNC) is a corporate organization that owns or controls the production of goods or services in at least one country other than its home country." Black's Law Dictionary suggests that a company or group should be considered a multinational corporation if it "derives $25 \%$ or more of its revenue from out-of-home-country operations." Therefore, our client would qualify, yet was still perceived as a Chinese company, due to the lack of a global production footprint, the very Chinese governance, management, and commercial practices, the shallow engagement with most

D. Depoux $(\varangle)$

Roland Berger, Shanghai, China

H. Wang and L. Miao (eds.), Transition and Opportunity, China and Globalization, https://doi.org/10.1007/978-981-16-8603-0_14 
local communities beyond commercial activities, the minimal impact on employment and its very Chinese brand recognition.

Being strong in revenue yet weak in globalization is a paradox for Chinese companies. Having benefited from a large domestic market and sparkling business innovation, Chinese companies are gigantic in size and entrepreneurial by nature. 133 Chinese companies are listed in the Fortune Global 500, surpassing the presence of American companies. However, only 29 of them scored over 20 in the Transnationality Index, while the top 100 western companies score over 50 on average. They certainly do not lack of the motivation to go abroad-they are actively expanding in global markets, dedicated to asset purchases to climb up the value chain, as Japanese companies did in the 1980s. Moreover, the best practices of western multinationals (MNCs) are in the playbooks of Chinese top executives. They believe that acquiring the global management know-how is simply a matter of time as China integrates into the world.

However, time will not stand still — the global market won't just wait for Chinese companies. Given the political polarization accelerated by the coronavirus pandemic, Chinese companies are increasingly challenged by the global business community. Under such circumstances, winning over global partners is a top priority. Amid the deteriorating global environment, Roland Berger is helping Chinese companies to transform by re-assessing their strategy, organization, and culture. We are more than aware that the conventional mindset of maximizing the efficiency of Chinese supply chains and increasing global sales revenue through a mono-culture organization does not fit today's value-driven world. It's not the time for Chinese companies to stop expanding their global footprint, but to leverage Chinese characteristics to be more globalized.

\section{With Political, Technological, and Regulatory Uncertainties, Traditional Management in Chinese MNCs won't Work on the Current Global Platform}

Unlike western MNCs that globalized in late twentieth century, Chinese MNCs nowadays face a deteriorating political environment. With the trend toward neo-liberalism in the 1980s, MNCs entered their heyday as they relocated industries to reduce cost and construct multilateral norms for global trade. However, after the 2008 financial crisis, the good old times were over. The side effects of the globalization, including accelerated unemployment and income inequality, created challenges for the political systems of western countries. On the one hand, misalignment between China and US lingers, manifested in the depreciation of US treasury bonds due to Quantitative Easing and the execution of the Pivot to Asia strategy. On the other hand, Mr. Trump's trade war, tech bans, and delisting have posed new challenges for Chinese companies. Although Mr. Biden is back on track with allies-friendly institutionalism, his value-driven diplomacy does not make business easier for Chinese MNCs, and 
most prior measures remain in place, while China is increasingly pointed out as an economic, technological, and political rival, threatening the long dominance of the USA.

With technological progress and novel regulatory frameworks, a disruptive global value chain creates new uncertainties for Chinese MNCs. After decades of growth in the semi-conductor and internet industries, the Silicon Valley model has challenged established industries, such as the European Auto Industry, in product definition, R\&D processes, corporate culture, and market competition. Naturally, digitization has triggered new regulatory frameworks, such as GDPR and digital sovereignty in the EU, the Data Security Law, anti-trust, and data security globally. Yet regulation extends beyond that. Fighting against climate change, regulators are promoting carbon pricing and more compulsory Environment Sustainability Governance (ESG) rules on trade and carbon border adjustment mechanisms in Europe, the USA and Japan, which will reshuffle global competitiveness. Yet it will take some time for the competition paradigm shift to reshape the global value chain. Chinese MNCs must rethink the fundamental logic of how to run truly global operations.

The old way of running MNCs does not fit Chinese companies. In an industrial economy, internationally business-friendly environments contribute to organizational path dependence. Such a context nourished a centralized, headquarterdominated culture, as MNCs could simply duplicate their production process, business models, and corporate management to thrive overseas. However, as the digital economy and political polarization decentralize the global market, maintaining the traditional central periphery has become increasingly futile. As a result, companies must adapt to a localized eco-system in strategy-making. Headquarters can still develop the overall strategies for each office, but the decision-making process must involve local office as well.

In previous decades, western MNCs had been trained in how to localize strategies in a cross-cultural organization and how to carefully manage government relations through lobbying or compliance. Nevertheless, such uncertainties appear to be unexpected and overwhelming even for them-let alone Chinese MNCs, which are facing an even more polarized political agenda globally.

\section{Despite All These Uncertainties, Chinese Companies Are Strongly Motivated to Globalize}

First, firms need to increase size and growth potential. Despite the tremendous demand in the domestic market, competition is intense. Due to information transparency and a culture of fast-adoption in China, once a novel business model works out, new market entrants tend to quickly imitate or simply duplicate such models, driving down profits and resulting in overcapacity. Facing the stagnation of sales and declining profits, companies must expand overseas in order to scale up their business. Expansion abroad can also help to achieve economies of scale, hence lowering costs. 
Second, multinationals can leverage their operations across multiple countries to exploit the most favorable economic conditions. With the presence in multiple locations across the world, companies can access more resources. While foreign MNCs used to set up their factories in China to take advantage of lower labor costs since China opened its market, many companies now choose to locate their supply chains in other emerging economies like Vietnam, Indonesia, and Cambodia, in search of labor productivity as well as innovation and technological capabilities (and circumventing tariffs). On the other hand, a flexible operating location makes outsourcing practices more convenient, as such practices can optimize operations and hence effectively cut costs. The adoption of the RCEP treaty will increase the regionalization of supply chains, driven by Chinese companies.

Third, Chinese companies need to promote their brands and corporate influence, transforming their image from "Cheap China" to "Brand China." Chinese businesses are becoming more aware of the power of branding in capturing consumers and securing larger profits, and are looking to increase returns by investing in their brands. Becoming an MNC would help transform their image abroad as well as domestically, thereby cultivating a new perception of China's brands. This will also be served by shifting from "Made in China" to "Designed and Engineered in China, Manufactured Elsewhere" a journey that Western companies have long accomplished-Why would it be different? Doing so, having more local impact outside of China, would also entail more respect by local governments, and make skepticism with Chinese investments a lot less relevant than today in a polarized world.

Fourth, Chinese and other multinationals can tap into vast resources of technological expertise by drawing upon the knowledge of a global workforce. When doing business overseas, a lack of knowledge of local business practices could be detrimental to a company's development, as previous experiences cannot be simply duplicated in a new region with different consumer practices and business environments. Hence, companies need to acquire local expertise. An MNC would have easier access to local labor markets and first-hand information of the local talent they need. Such information superiority is essential to industries that require specific technical expertise, such as infrastructure, fintech, engineering, etc. By becoming MNCs, Chinese companies can also acquire foreign talent that can help them reinforce their technological and management competencies.

Furthermore, geography and portfolio diversification can contribute to different markets and compound benefits. Creative portfolio development strategies that have led some traditional companies to venture into consumer markets would bring about higher growth, such as financial services, entertainment, hospitality, tourism, or other non-core activities. These companies could eventually develop into conglomerates, where their legacy business could either be one pillar, with restructured domestic and international capacities, or gradually phased out, while other businesses are acquired and built up, nationally and internationally. The first phase of this development has been awkward with large Chinese conglomerates randomly investing in scattered activities with limited capital mobilization or operational synergies and leveraging always heavier balance sheet. This would be a better alternative to utilizing state as well as private capital and loans to build resilient conglomerates. This is somewhat 
comparable to the trade- and finance-driven development of Korean and Japanese trading houses in the previous century.

\section{Chinese Companies Are in the Fortune 500, but Only a Few Are Seen as MNCs}

Despite being some of the world's largest companies, most Chinese companies haven't become true MNCs yet. Many leading Chinese companies with considerable income overseas are still perceived as Chinese companies rather than global corporations. Some giants do not even bother to develop significant activities overseas, as the domestic market so far has always been more attractive and easier to grow. We call this phenomenon the "black hole" of a domestic market, attracting all human and financial resources. Even for those with a global presence, brand recognition overseas is hardly comparable to global champions such as Coca-Cola, GE, Disney, Toyota, Sony, and Google. For instance, Lenovo now generates $72 \%$ of its revenues outside of China and has six nationalities in its top management committee and 17 nationalities in its top 100 executive circles. Yet such achievement attributed to foreign acquisition of IBM, while Lenovo's technological innovation and brand awareness remain weak in global markets, hence falling short of achieving true MNC status. It seems that generating revenue from abroad is not enough to become an MNC, but then what defines a multinational?

MNCs are defined not only by their scale of sales or market shares overseas but also by their global influence. First and foremost is branding. Very few large Chinese companies have well-known brands outside of China. Many of China's biggest companies have been focused on building a strong brand identity at home rather than internationally. Among the 133 Chinese companies listed in the Fortune 500, only a few have scaled up thanks to their global presence. China is the largest source of imports to the USA, but two 2013 surveys showed that only $6 \%$ of respondents could name at least one Chinese brand.

Second, an integrated and unique development plan is necessary. Just as the stability of a country's development requires a clear plan, so does that of a corporation. A clear plan not only has the ability to effectively guide the development of a company but also consolidate a corporate spirit in terms of its core values, strategies, and potential impacts on the future business landscape worldwide. For instance, one of the major reasons why people have so much faith in Tesla today is that its CEO, Elon Musk, has had followed his business plans for decades, making the story of Tesla not only an example but also a legend, adding tremendous value to the corporation.

An integrated organizational structure is also crucial in terms of international management. When carrying out international projects, MNCs usually feature a localized operational team that is fully integrated into corporate decisions. Meanwhile, many MNCs conduct international projects that nurture new talent and create 
a pool of international ready executives who can provide intuitive guides for corporate development. Most MNCs also feature foreigners in management structures internationally as well as domestically.

The final point lies in the influence of global technology. MNCs have played a major role in stimulating technological development across multiple industries. Transformational technology necessarily contributes to the long-standing influence of a corporation. Take one of the most classic examples - the streamlined production model of Ford transformed not only the automotive industry but also the manufacturing industry. Another example is Apple's unique iOS operating system, which transformed the way people use their phones.

In looking back at the process of globalization, Chinese companies often proactively buy foreign firms to achieve economies of scale, technology upgrades, and expansion in new markets, but still fall short of becoming true MNCs

The globalization of Chinese enterprises has gone through several stages. Early on, globalization was led by trade and trade-related finance, particularly driven by the government mandate to "go abroad" in 1990s. Chinese State-Owned Enterprises (SOEs) invested heavily abroad (particularly in developing countries) with the primary purpose of securing natural resources. The following decade witnessed a significantly greater spread of overseas Chinese affiliates. CNOOC, State Grid, Southern Grid, Petrochina, Sinopec, Huaneng, and Guodian leveraged newly listed companies to engage in international activities, mostly through minority stakes in peer companies or projects. However, only a few of those companies had clear intentions of competing in international markets, and problems often arose due to the limited scale and fragmentation of many of the projects, and lack of experience in coordinating operations overseas.

In the second phase, Chinese companies started to engage in international M\&A to acquire key technologies and assets to support domestic development. China's investment in mature markets such as the USA and Europe reflected its pursuit of advanced technologies. Chinese companies invested a record USD 45.6 billion in the US economy through 142 transactions. Major transactions included AnBang Insurance's investment in Strategic Hotels \& Resorts, and Haier's acquisition of GE's consumer appliance subsidiary. Europe continues to be a favorite destination of Chinese investors, with a more focused technology and know-how approach, with almost USD 80 billion invested in 2016. Top deals include ChemChina's bid for Syngenta, Tencent's investment in Supercell, and Midea's acquisition of the German company Kuka.

However, when investing abroad, Chinese businesses are usually very proactive, sometimes taking on excessive risk. In particular, there are more and more unsolicited bids from Chinese companies looking to expand overseas that are facing protracted and costly takeover battles. Other issues are related to culture, management, legal affairs, compliance, and human resources. The majority of Chinese buyers do not have a solid post-merger integration plan. More often than not, they simply pump financial liquidity to the target company and let the existing managers operate the business. Gradually, some Chinese companies have realized that it's extremely difficult to 
integrate $\mathrm{R} \& \mathrm{D}$ from a target company into the mother group, let alone to maximize the synergy between the global markets and Chinese production.

\section{What is the Chinese Way of Becoming Multinational?}

Despite the challenges of becoming true MNCs, many well-known Chinese groups have managed to achieve some degree of success in fields across the industrial, commercial, and services sectors. These include companies like Huawei, Fosun, Haier, TCL, and ChemChina. But what unique features and successful experiences of Chinese companies can be leveraged to help them become true MNCs?

Perhaps most importantly, the Belt and Road Initiative (BRI) has created a friendly environment for Chinese companies to expand internationally. China enjoys a strong policy framework that not only ensures domestic certainty but also serves as a backbone for Chinese companies' global integration. China has launched a series of policy initiatives to enhance trade and political relations between China and other countries, allowing China to boost its growth by exporting its capital, technology, and capacity globally. For instance, the BRI announced by President Xi Jinping in 2013 promotes economic cooperation amongst countries along the "Belt" and "Road" routes in AfroEurasian regions, which also stimulating business opportunities from infrastructure to manufacturing and finance. Moreover, the recently signed Regional Comprehensive Economic Partnership (RCEP) creates a stable and predictable business environment for regional trade and investment.

At the same time, the Chinese entrepreneurial spirit, which emphasizes hard work, provides effective labor resources that help corporations thrive. China's spirit of working hard is based on the belief that hard work today will bring about prosperity tomorrow, which is firmly rooted in the culture. Such a hardworking spirit and the will to make a difference originated in the 1980s, when China's government encouraged the construction of infrastructure to promote the economy. Alibaba's founder Jack Ma has a famous line: "Yesterday is hard, today is hard, but tomorrow-tomorrow will be beautiful." Many of China's legendary entrepreneurs such as Jack Ma come from humble beginnings, which means they often value high asset turnover and good timing over perfection, expecting to sustain high rates of growth and comfortable with a heady pace. As a result, many large Chinese companies share a stringent management style (i.e. a 996 work schedule), especially in technology (Huawei, Alibaba, Tencent, etc.). Despite controversies over such management styles, this hardworking spirit, shared by managing directors and employees alike, has resulted in high productivity and rapid development of these giant companies.

Growing innovation leadership has facilitated the internationalization of Chinese companies. China has competitive advantages in the transport equipment industry, especially railway equipment, due to its advanced technology, lower costs, and expanding networks. In the energy sector, total Chinese investment in power generation and power transmission has surged since 2011, mainly driven by large acquisitions in Europe, South America, and Australia by China State Grid, as well as the 
"Big 5" Chinese power generators and greenfield investment in renewable energy. In the machinery industry, China is pushing its companies to upgrade and automate by increasing research budgets and making more higher-value products. It has also encouraged companies to acquire European and US rivals with advanced technology. Technology companies such as Lenovo and Huawei are paving the way for Chinese brands to globalize, in spite of increasing political and regulatory challenges, across the planet.

As video apps like TikTok and other social media giants bring innovative internet business models that threaten existing global platform giants, Chinese MNCs are perceived as potential disrupters, not just as followers. China has become an innovation giant that defines novel business models, notably in the field of consumer markets, characterized by customer-centric innovations. The country has nourished leading tech companies such as Alibaba, Tencent, and Baidu, which have invested heavily in tech innovations.

In addition, burgeoning PEs and PVc have been facilitating the innovation drive. A sign of increasingly mature capital markets in China, financing activities by PEs and VCs are becoming more popular, driving the growth of promising start-ups or growth firms that could become the future MNCs. According to data from the China Foundation Association, PE funds invested RMB 739.2 billion in domestic companies in 2019. As of 2019, 86,254 investment projects have been conducted, with an investment amount of RMB 6.24 trillion, an increase of $17.77 \%$ relative to 2018. The most heavily involved industries include computer applications, capital goods, medical devices and services, medical biology, and raw materials.

Innovations in the domestic market can be efficiently leveraged when expanding overseas. TikTok's mother company ByteDance was established in 2012 and has publicly acquired more than USD 72 million in financing in less than 10 years, which effectively supported its rapid development. Building on the experience in other apps like Toutiao, TikTok managed to renovate on a global scale the notion of "new media" like short videos, which has transformed digital marketing from relational marketing to interactive marketing with a larger range of influence and higher level of stickiness. By the end of 2020, TikTok had been downloaded 1.9 billion times worldwide, with a DAU over 3.3 million.

\section{Hurdles to Overcome and Solutions}

To sum up, increasing global trade, the constant deepening of globalization and technological advances have offered more opportunities for Chinese enterprises to go global. Even in 2020 and the first half of 2021, the incredible resilience of Chinese supply chains has confirmed that Chinese MNCs will keep playing a major role as manufacturing power houses. 2021 will be a crucial year for Chinese companies that have the ambition to go global. Both national and international priorities highlight global cooperation and have opened up unprecedented opportunities for Chinese enterprises to invest abroad. However, volatile political and economic conditions 
also require Chinese companies to become more strategic, efficient, competitive, and sustainable to achieve these goals. Adjusting business models will be critical to become true multinationals, therefore circumventing some of the political and economic hurdles of solely being "Chinese companies."

Some of Roland Berger's Chinese clients have achieved growth and better business results through successful globalization and international development strategies with clear geographic and/or industry focuses. Companies need to first establish clear strategic plans and goals then implement international expansion according to actual external and internal circumstances with a clear focus on regions in order to achieve the optimal allocation of global resources. For instance, Chinese investment in strategic natural resources such as oil and gas by large SOEs has long focused on securing raw materials in emerging markets like South Asia, Central Asia, Africa, and South America, which turned out to be successful. However, such a strategy is not enough to ensure a well-received global brand image. To consolidate their global position, it is imperative to establish a clear and focused development roadmap. One possible measure would be to actively engage other global giants in their respective fields to co-develop resources, as is the case in the nuclear sector.

Governance of international development and operations. Chinese companies should improve corporate governance structures and establish an institutional system in line with international markets, local government, and business communities, while at the same time integrating international standards into their development strategies. This is particularly true in the execution stage, where overseas management could be strengthened by either grooming their own managers or recruiting global talent. A much higher and visible proportion of non-Chinese leaders and managers is indispensable if they are to be regarded as true MNCs.

Team China: cooperation across different companies. Companies that have been operating overseas for a longer period of time have more experience, which enables them to run their businesses better than those who have only ventured overseas recently. After years of exploration and experimentation, some large Chinese companies with more experience have formulated a set of models and practices. Their philosophies, policies, and management practices could potentially set standards for other Chinese companies, and their local market resources can be shared among small-sized companies and newly globalized companies. We suggest that companies unfamiliar with foreign markets learn from their industry peers and select an appropriate role model, perhaps even partnering with them to find the most effective way to become more international.

Partnership strategies with foreign companies to enter third-party countries. Some Chinese companies lack specialized partners with local influence to assist in their international expansion process. Typical local partnerships include, but are not limited to, local business partners, professional service firms, and some non-government organizations (NGOs). By seeking joint venture opportunities and strategic alliances with local partners, Chinese companies can both become stronger and reduce risk. This is not so innovative and compares well with the experience of Western companies developing in China through joint-ventures, even if most were initially mandated by equity caps and restricted market access. Such cooperation 
provides a learning curve and a de-facto mutual interest, until interests can diverge, or scale demands another model. By leveraging professional firms with overseas experience, Chinese companies can also reduce information asymmetry and enhance decision-making capabilities. Chinese companies should also increase cooperation with international organizations, NGOs, and other local stakeholders. Due to their third-party status, NGOs command credibility across the world and are thus more readily accepted by stakeholders in host countries. Forming close ties with these organizations can attract public attention to Chinese companies and expand their community influence.

Integration strategies and implementation after large overseas acquisitions. One major gap that Chinese companies face when considering and conducting overseas acquisitions is post-acquisition integration. As mentioned earlier, this too often boils down to a simple take-over and a "business as usual" approach. While a lack of focus and strategy in international acquisitions might lead to overly proactive and blind capital investment, strategic investment can, on the contrary, effectively help construct a global image for corporations. For example, ChemChina followed a systematic "reverse take-over" process by initially acquiring divested, sometimes non-core assets of other chemical companies, which helped them obtain resources and access to broader markets, using these newly acquired companies to create internal organizational and managerial pillars.

Post-acquisition integration should start well before the transaction itself. Integration of each acquired company is different and depends on multiple factors:

- Financial, operational, and industrial objectives pursued in realizing the transaction;

- Level of integration can range from keeping it "as is" as a new subsidiary, financially or strategically steered, to a full merger and integration into the parent company; intermediate integration levels include the integration of specific functions, business segments, or geographies;

- Development of the underlying consumer market and competitive positioning of the acquired/merged company;

- Original intention of the parent and the acquired companies from a financial, strategic and cultural standpoint and level of transformation expected after the transaction (e.g., restructuring, performance improvement, or accretive acquisitions creating the opportunity for enhanced performance due to improved synergy);

- Cooperation between management and operational teams of the parent and acquired companies, cultural differences between the two companies (history, performance, management styles and processes, decision-making, etc.).

Moreover, an acquisition or a merger does not stop when the transaction is signed. Instead, integration needs to be carefully planned and executed over time in order to achieve sustainable returns. In a regular Roland Berger survey of 130 international executives, across 15 industries, that were involved in acquisitions and mergers, $80 \%$ of failed post-acquisition integration was due to incomplete integration and lack of synergy management, and $50 \%$ was due to insufficient management of the 
differences in corporate culture. This is particularly the case for cross-border integration, including Chinese-Overseas transactions. Integration activities are not "rocket science," but they do rely on preparation, process management, speed of execution, and experience. This is what our Roland Berger consultants usually bring to our clients.

The success of an acquisition or merger is usually measured only after a few months/years, depending on the size of the transaction, and on other criteria (such as the realization of top and bottom line synergies that were expected during the preparation stage, and/or actual integration of the two companies and the creation of a seamless and single organization and culture). This is why we recommend that Chinese companies consider international acquisitions that have a more professional and proactive approach toward integration. The following is a checklist of postacquisition integration building blocks.

1. Execute transaction-related activities without disrupting on-going business and integration processes;

2. Define an underlying vision and strategy for the acquisition and specific integration objectives and approaches;

3. Secure key people and manage corporate culture differences proactively;

4. Identify key challenges for integration and for NewCo;

5. Design an integration structure;

6. Define NewCo governance and organization;

7. Ascertain and activate synergies;

8. Communicate proactively and clearly with all stakeholders.

Beyond the practicalities of developing international assets within their portfolio of activities, Chinese companies should also use soft power to increase cultural integration and influence, following the examples of Haier or Huawei.

Unfamiliarity with local customs, lack of communication, cultural differences, and misperceptions are major issues that confront Chinese companies. Cultural differences are the most prominent issue facing overseas labor relations, and some Chinese companies have yet to build effective communication mechanisms to exchange ideas with stakeholders in host countries. One way to resolve this is to give higher priority to the training and promotion of local employees and to increase the number of local managers. For example, Haier and Huawei adopted an expert-driven approach when expanding overseas, with a proven ability to integrate with local markets through the acquisition of local talent, development of local products, and staffing of R\&D in overseas centers. By doing so, Chinese companies can better navigate cultural barriers and build trust with potential foreign partners. More importantly, instead of solely focusing on profits, Chinese companies should keep an eye on local communities by organizing cultural exchanges, participating in local infrastructure projects, providing vocational trainings, and running public welfare programs for underprivileged groups. 
Ultimately, if Chinese enterprises hope to succeed in their drive to expand overseas, they need to focus on formulating international development strategies, improving communication mechanisms with local stakeholders, establishing international corporate governance, promoting partnerships, and strengthening integration/implementation capabilities.

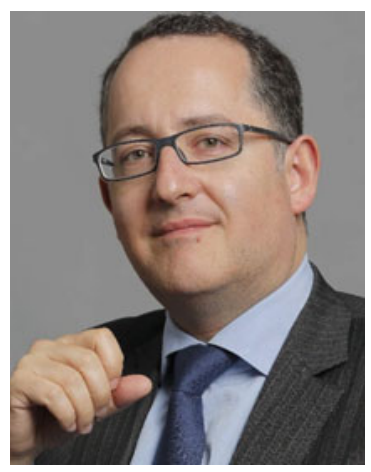

Denis Depoux is Member of the Management Board and the Global Managing Director of Roland Berger. He has a master's degree and a post-graduate research degree in organization sociology from Sciences Po Paris. He began his career in China in 1993 with French energy giant EDF. He joined Roland Berger in 2001, focusing on the energy and environmental sectors, and sharing his strong consulting expertise and rich industry experience in the USA, Europe, and Asia. Depoux has been actively supporting the firm's Greater China operations since 2007. Since moving to Shanghai in 2015 , he has contributed greatly to the transformation of Roland Berger in Asia. Since 2020, Denis Depoux has been one of the three Global Managing Directors of Roland Berger.

Open Access This chapter is licensed under the terms of the Creative Commons AttributionNonCommercial-NoDerivatives 4.0 International License (http://creativecommons.org/licenses/bync-nd/4.0/), which permits any noncommercial use, sharing, distribution and reproduction in any medium or format, as long as you give appropriate credit to the original author(s) and the source, provide a link to the Creative Commons license and indicate if you modified the licensed material. You do not have permission under this license to share adapted material derived from this chapter or parts of it.

The images or other third party material in this chapter are included in the chapter's Creative Commons license, unless indicated otherwise in a credit line to the material. If material is not included in the chapter's Creative Commons license and your intended use is not permitted by statutory regulation or exceeds the permitted use, you will need to obtain permission directly from the copyright holder.

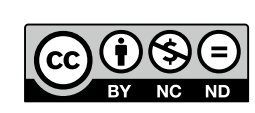

